\title{
Experimental Study of Submerged Vanes in Intakes under Sediment Feeding Conditions
}

\author{
Aslı Bor Türkben ${ }^{1, *}$ \\ ${ }^{1}$ Department of Civil Engineering, İzmir University of Economics, 35330 İzmir, Türkiye
}

\begin{abstract}
Sediment is transported along the river flow and deposited in the mouth of the intake structure over time and reducing the water intake capacity. Nowadays, many water intake structures lose their function and are closed to operation. To deal with this problem, recently, submerged vane application has offered a practical and economical solution. The aim of this study was to evaluate the efficiency of three vane installations under sediment feeding conditions by comparing the bed topography before and after vanes were installed. For that purpose, experiments were carried out in a laboratory channel running for 90 -degree intake angle. Three vanes were installed in one column at near the intake entrance. The vanes dimensions were equal to; $3 \mathrm{~cm}$ height, $12 \mathrm{~cm}$ long, $10 \mathrm{~mm}$ thick, and aligned with $\alpha=$ $20^{\circ}$ angle to flow direction. The tests were run until equilibrium was reached, i.e. when the outgoing solid discharge was equal or larger than $90 \%$ of the incoming. Once the bed topography remained stable, bed and water level surfaces were measured. tests were carried out by feeding sediment from upstream of the main channel.
\end{abstract}

\section{Introduction}

Sediment may enter the diversion channel causing a loss in performance or even worse, uncontrolled movement of the sediment may cause turbine failure. Another problem is that if there is a lot of deposition in front of diversion channels, the performance of intake structure is negatively affected due to the loss of flow rate. Therefore, accurate prediction of scour and deposition is mandatory in order to find a solution allowing the control of the sediment transport. There are several methods for controlling the sediment transport. Submerged vanes provide a practical and economic way to control sediment transport. They can also be used to control riverbank erosion as well as to improve riverbed morphology. Submerged vanes generate a secondary circulation in the flow and change the magnitude and direction of the bed-shear stresses. As a result, the riverbed aggrades in one portion of the channel and degrades in another. Thus, sediment accumulates in the main channel in a controlled manner and preventing it from entering the water intake channel. Previous researchers performed experimental and numerical studies to describe submerged vane behavior on the sediment transport. May researchers studied the various aspects of vane design for sediment controlling at intake structures. [1-5]

\footnotetext{
* Corresponding author: asli.turkben@ieu.edu.tr
} 
Kasthuri and Pundarikanthan [6] investigated vortex dimensions and flow separation at the entrance of a diversion channel. They showed that increasing diversion ratio can reduce the dimensions of the vortex area. They also showed that if the diversion ratio is greater than " 0.7 ", the dimensions of the vortex area stays unchanged. Odgaard and Spoljaric [4] showed that small angles of submerged vanes perform better, and vanes installed at angles greater than 250 cause unexpected scour around the vanes. Nakato et al. [7] studied at MidAmerican Energy Company's Bluffs power station for producing a scour trench in front of the water intake and so control of the sediment entering.

Barkdoll et al. [8] showed that using vanes at the entrance of the diversion channel, the effectiveness of the vanes decreases as the diversion ratio increases. According to their study, if the diversion ratio is less than " 0.2 ", then the amount of the sediment that enters into the channel is less.

There are a lot more studies about submerged vanes. However, the common part of all these studies is that every investigation was conducted without sediment feeding into the main channel. In this study, the results of experiments with and without submerged vanes installed in front of a diversion channel placed at an angle of $90^{\circ}$ with the main channel are presented. The experiments are conducted under sediment feeding with steady flow conditions. The aim of this study is to analyze and compare amount of the sediment entering into the intake with and without vane conditions.

\section{Experimental Set-Up}

Experiments were carried out in $12 \mathrm{~m}$ long and $1 \mathrm{~m}$ wide rectangular main flume and $15 \mathrm{~cm}$ wide, $5 \mathrm{~m}$ long 900 intake flume, located at hydraulic laboratory of the Instituto Superior Técnico (IST) in Lisbon. The bottom slope of the main channel was 0.007. Figure 1 shows the experimental set-up. The constant water discharge in the flume was controlled and preset by a speed control unit attached to a pump system with $\pm 0.1 \mathrm{l} / \mathrm{s}$ accuracy located at the upstream. The main tank and rectangular basin were at the downstream end of the flume. There was a sediment recovery system at the downstream end of the main channel consisting of a sediment tramp, bottom outlet and sediment recovery tank. A conveyor belt with a velocity regulator device was used for sediment feeding in the inlet of the flume.

The flow discharges of the main and intake flume were $Q_{m}=451 / s$ and $Q_{i}=51 / s$ respectively. The flume bed was covered by uniform sand with a mean diameter of $\mathrm{d}_{50}=0.85$ $\mathrm{mm}$ and a geometric standard deviation equal to $\sigma=1.35$ which implies that the sediment can be assumed as uniform. Sediment feeding rate was $\mathrm{Q}_{\mathrm{sm}}=0.5 \mathrm{~kg} / \mathrm{min}$ for each test. The flow depth was kept $d=12 \mathrm{~cm}$ in both tests. Three vanes are installed in one column. Rectangular submerged vanes of $5 \mathrm{~mm}$ thickness of height $\mathrm{H}=3 \mathrm{~cm}$ and length $\mathrm{L}=9 \mathrm{~cm}$ were used according to suggestions of Herrero et. al [9], Odgaar and Kennedy [10], Odgaard and Wang [11]. Single row submerged vanes were placed at angle $\alpha=20^{\circ}$ to the main flow direction with vane spacing $\delta_{\mathrm{n}}=9 \mathrm{~cm}$ and vane to bank distance $\delta_{\mathrm{b}}=15 \mathrm{~cm}$ (Figure 2). Details of flow conditions are presented in Table 1.

Table 1. Experimental Flow Conditions.

\begin{tabular}{|c|c|c|c|c|c|c|}
\hline $\mathbf{b}_{\mathbf{i}} / \mathbf{b}_{\mathbf{m}}$ & $\mathbf{d}$ & $\mathbf{Q}_{\mathbf{i}} / \mathbf{Q}_{\mathbf{m}}$ & $\boldsymbol{\delta}_{\mathbf{n}} / \mathbf{H}$ & $\mathbf{H} / \mathbf{L}$ & $\mathbf{H} / \mathbf{d}$ & $\mathbf{\alpha}$ \\
\hline 0.15 & $12 \mathrm{~cm}$ & 0.11 & 3 & 0.33 & 0.25 & $20^{\circ}$ \\
\hline
\end{tabular}

"Where; $b_{i}$ and $b_{m}=$ intake and main flume width respectively; $d=$ flow depth; $Q_{i}$ and $Q_{m}=$ intake and main channel discharge respectively; $\delta_{n}=$ vane spacing; $H=$ vane height; $L=$ vane length and $\alpha$ $=$ angle of vanes. 


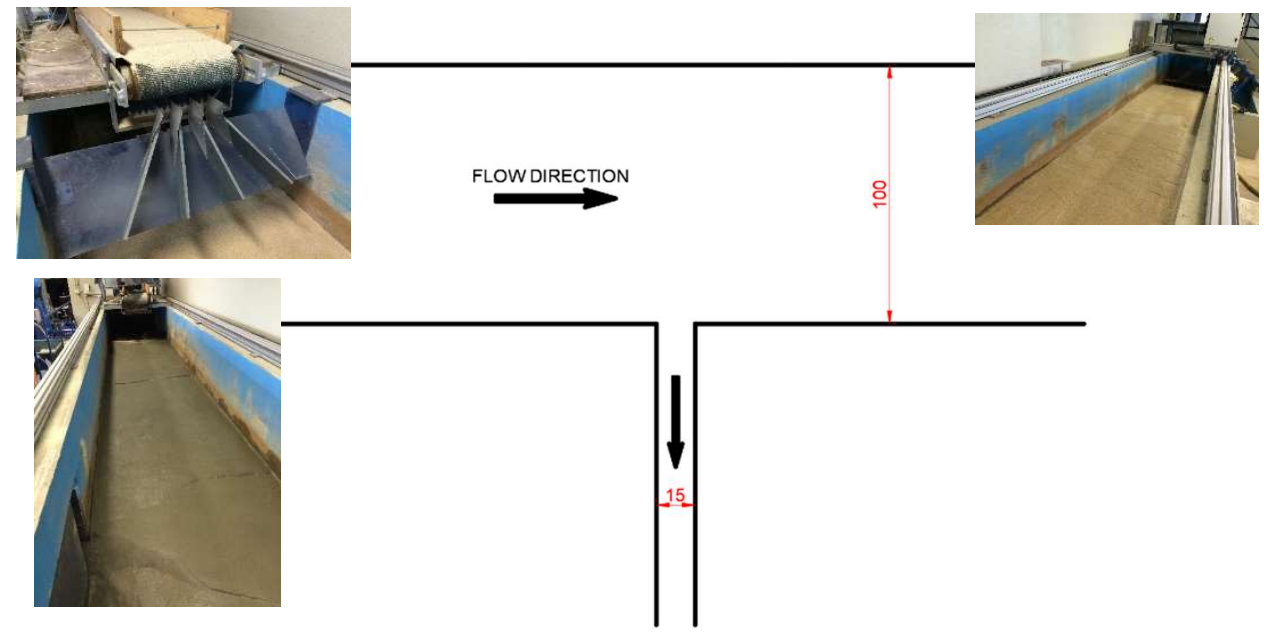

Fig. 1. Experimental Setup.

Fig. 2. Layout of the vanes.

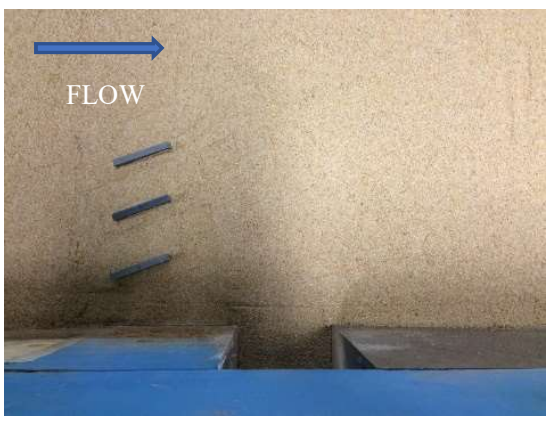

Bed elevations were measured using a Mini-EchoSounder probe (UltraLab UWS) in main and intake flumes with $\pm 1 \mathrm{~mm}$ accuracy by topographic surveys. The water depths were measured by ultrasonic limnimeter with $\pm 1 \mathrm{~mm}$ accuracy. The robotic arms instrumentation was installed on an automatic movable frame in $\mathrm{X}, \mathrm{Y}$ and $\mathrm{Z}$ directions in the main and intake flume and were moving along the flume in order to record bed and water elevations at the same time. During each experiment 22 longitudinal bed elevation and water surface profiles laterally spaced by $\Delta Y=4 \mathrm{~cm}$ along the main flume were measured. On the other hand, at the same time another robotic arm was used to determine bed topography and water surface along the intake flume was situated in the middle of the flume and it moves a distance of $50 \mathrm{~cm}$. The flume bed was flattened before each experiment and water was supplied gently without causing any disturbance. For both main and intake flume, bed elevations were recorded before the experiment starts. During the experiments, the backwater effect at the downstream end was prevented by a tailgate. Once the system was full of water with main channel discharge and adjusted to the required value and then suction pump was used for taking water inside from the intake channel. After that, discharge and sediment feeding rate were adjusted to required values and downstream tailgate was slowly lowered till the downstream water depth reaches $12 \mathrm{~cm}$ that corresponds to the approximated normal depth determined the Manning Formula. Incoming sediment rates were determined by weighing of sediments collected in the sediment recovery tank at intervals of facility $\Delta t=1.5 \mathrm{~h}$. Bed topography and water surface elevations were systematically recorded during the tests at $\mathrm{t}=1.5 \mathrm{~h}$ at $\mathrm{t}=9.0 \mathrm{~h}$ 
and at when equilibrium was reached. Equilibrium condition was reached after 12 hours and tests were stopped at $\mathrm{t}=13.5 \mathrm{~h}$.

\section{Results and Discussion}

Figure 3. shows the bed topography with and without vanes at the tests $\mathrm{t}=1.5 \mathrm{~h}$ at $\mathrm{t}=9.0 \mathrm{~h}$ and at the state of equilibrium condition $t=13.5 \mathrm{~h}$. In the absence and presence of vanes cases, scouring area was observed at the corner of the downstream wall of the intake flume at the beginning of each experiment and it gradually grow up, that's reason secondary flow caused in this area. The erosion hole progressively expands to the area of the main flume downstream. For with vane experiment the scour hole area stretches with lower depths next to the wall of the main flume side. At the same time, sediment is deposited in the recirculation area in the intake flume, next to the upstream of the main flume with lower velocities. For without vane experiment the deposition occurs with higher values than with vane experiment case. The second recirculation area occurred in the main flume, before the intake flume and in front of the other wall of the main flume, sediment deposited in those areas. Sediments continuously came into the intake flume so that it exceeded the sediment transport capacity and bed slope increased. The upstream from the diversion is called flow dividing surface and it separates the flow into parts, one goes into the intake flume and other goes on the main flume downstream. Due to the lower velocities in that zone it is easier to counteract the centrifugal force and change the direction of this part of the flow (Neary et. al. ,[12]). It is fair that for with vane experiment case, the bed forms keep traveling downstream without interruption. Figure 4. shows intake structure sedimentation zones.

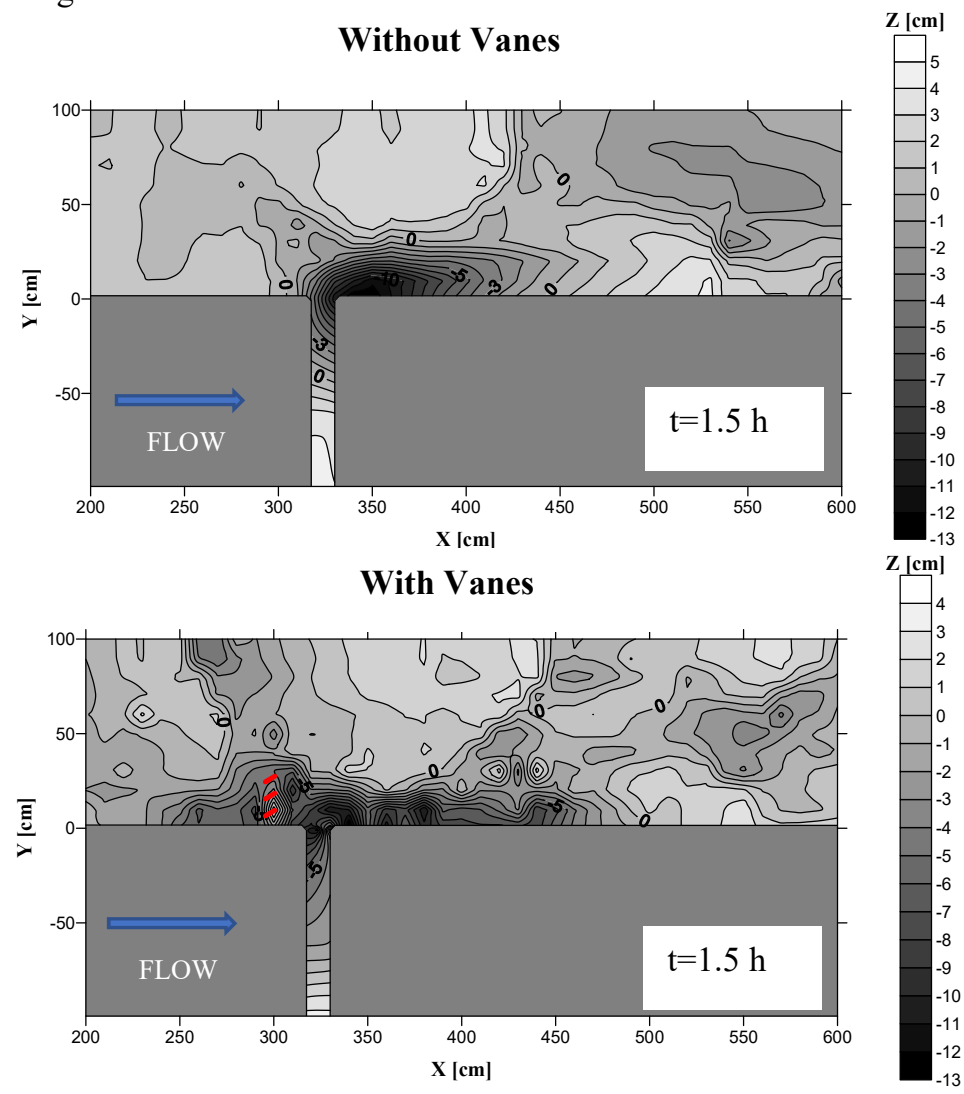



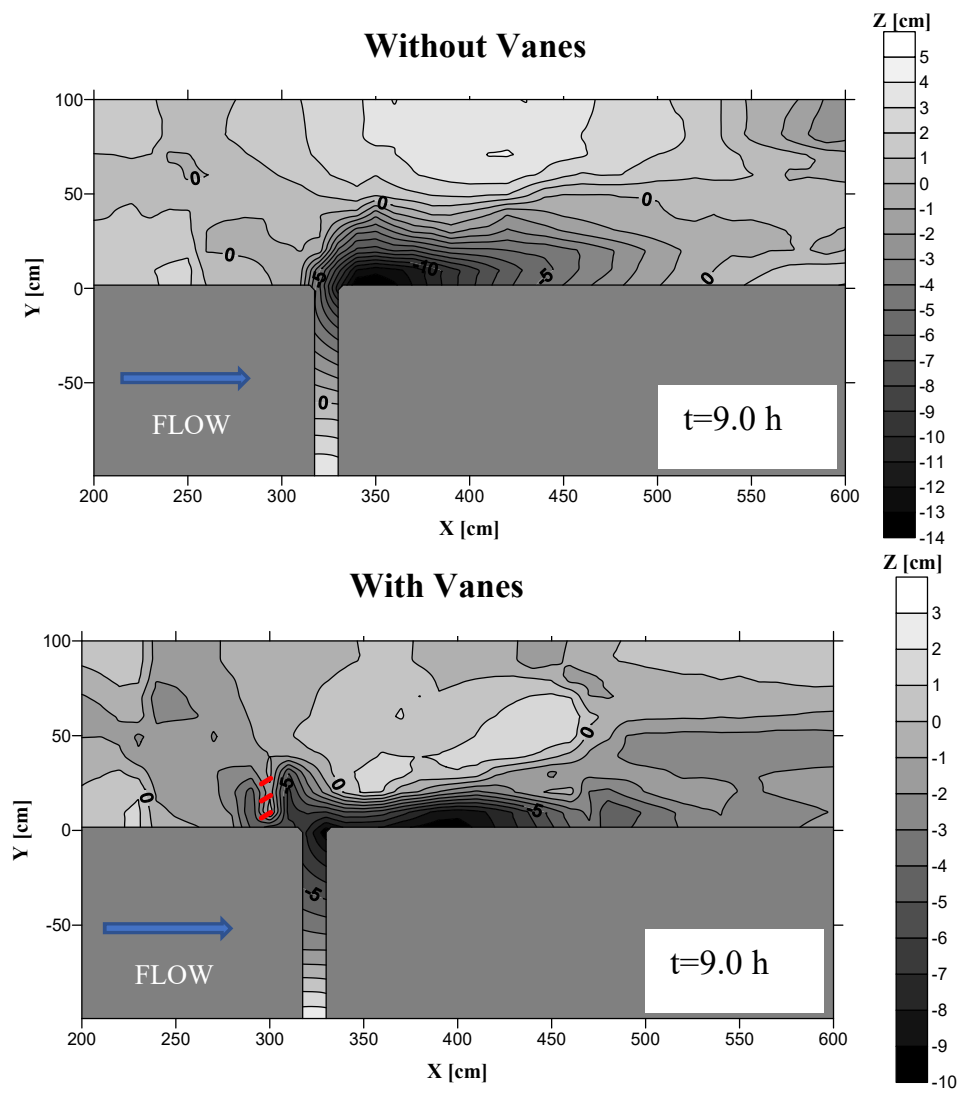

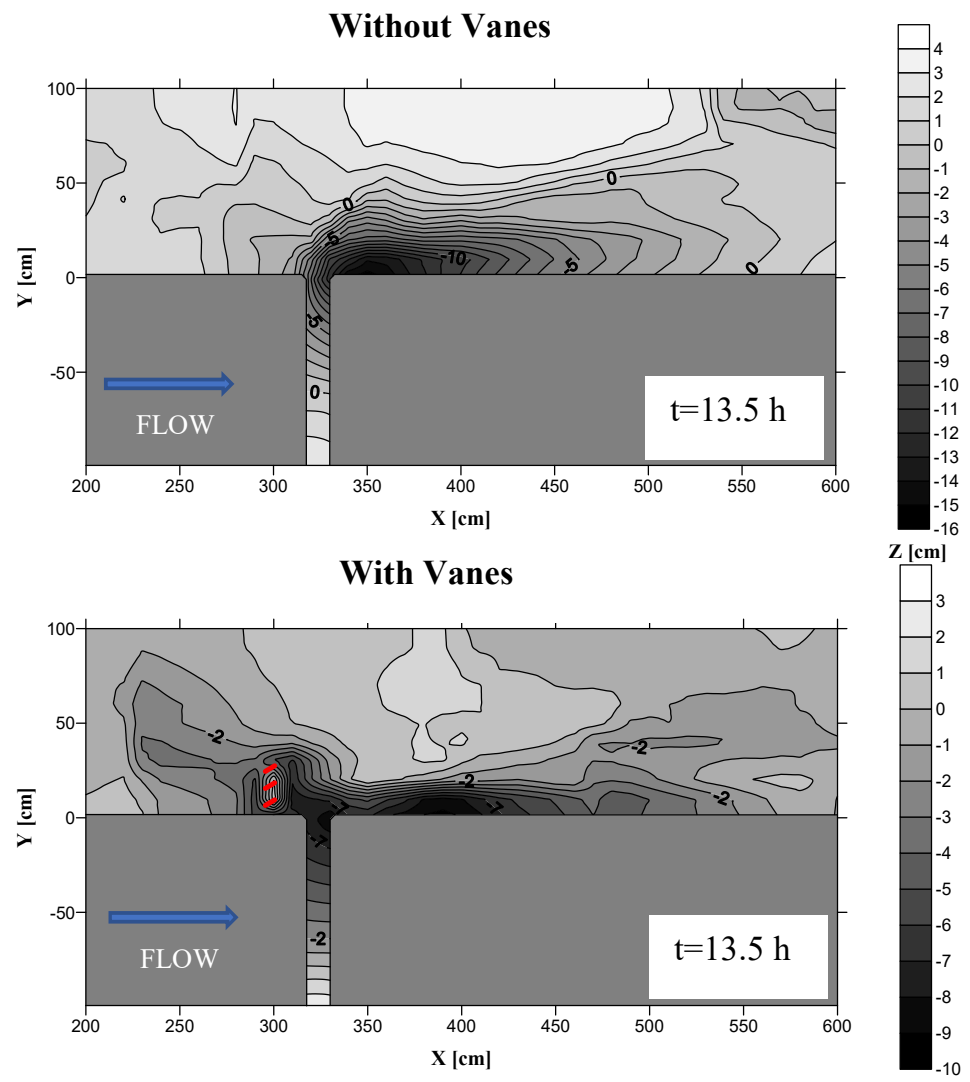

Fig. 3. Comparison of the bed topography for without vane and with vane tests in intake flume area.

Compare without vane and with vane experiments, the scouring area with higher depths next to the wall of the intake was observed for without vane test, however at this corner seems to moved along the downstream of the flume with vane experiment. On the other hand there is less deposition in the recirculation area and in front of the other wall of the main flume and other recirculation area dissipated along the main flume for with vane experiment. Scour zone is formed and developed in front of intake and around the vanes (Figure 3 and Figure 5).
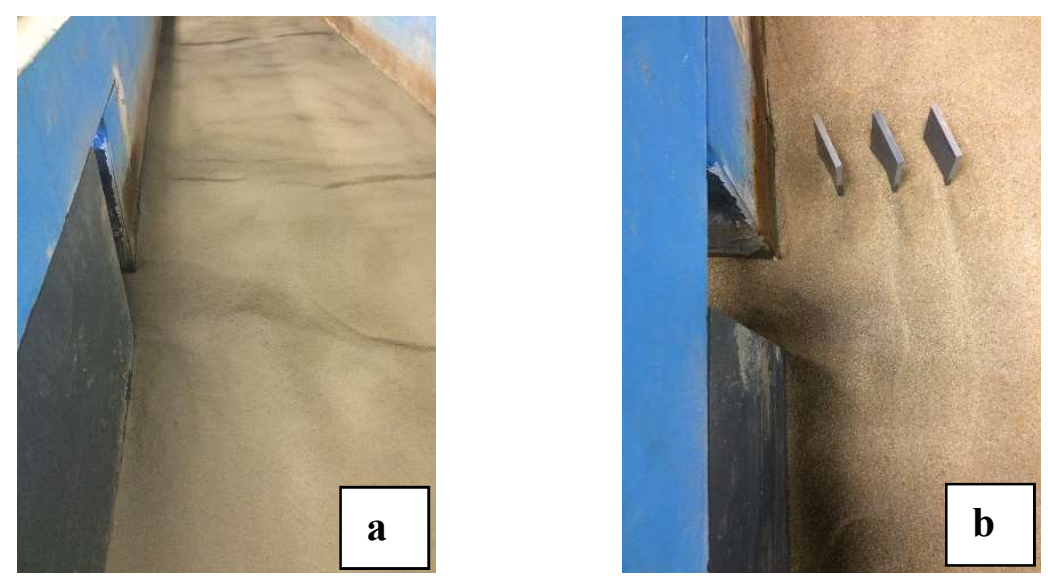

Fig. 4. Intake structure sedimentation zones scheme with vane and without vane experiment. 
The bed elevation sections for each experiment at equilibrium state in intake axis are presented below (Figure 5). It can be say that vanes considerably reduced the amount of sediment by $20 \%$ in the intake flume. The depth and size of the scour increased by without vane experiment. Also erosive capacity of the flow at the location of the intake also increased with time. The experiments reached equilibrium after 13.5 hours.
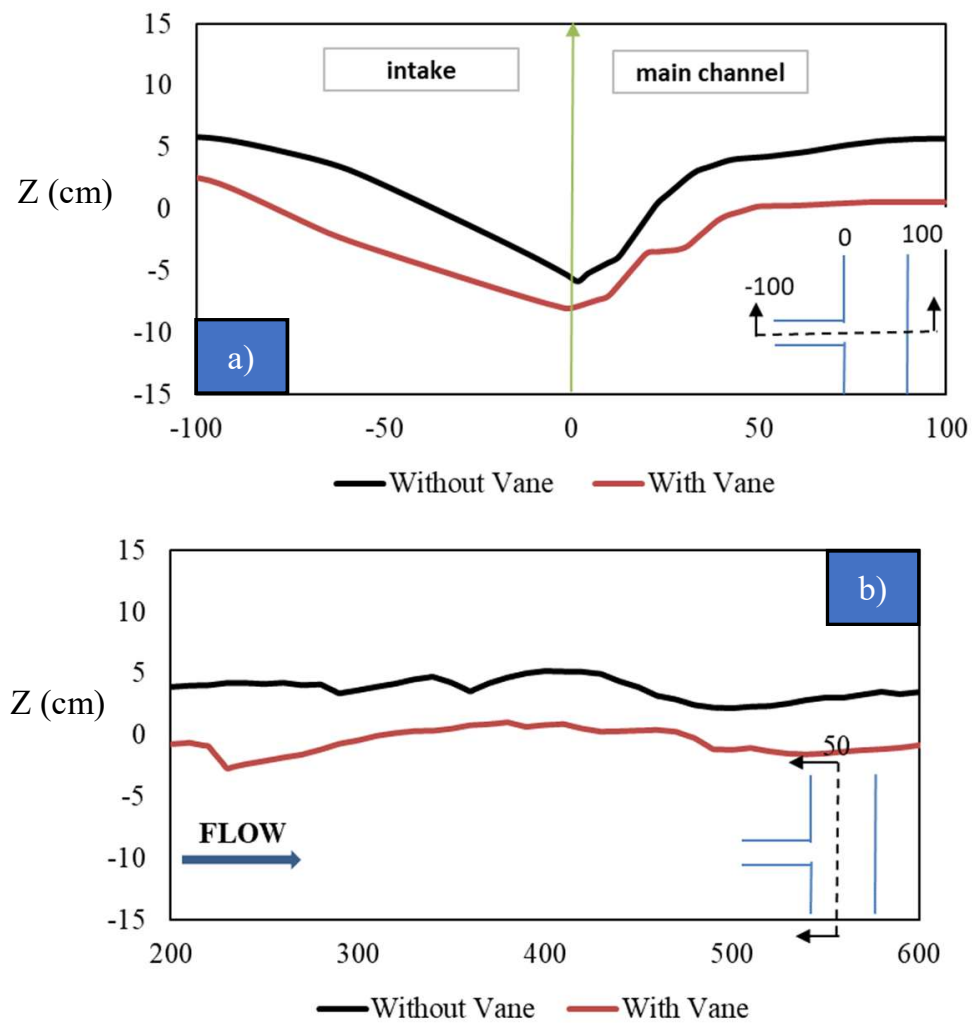

Fig. 5. Bed elevation graphs with vane and without vane experiment a) in the intake section b) in the main flume section.

\section{Conclusion}

In this study, submerged vanes were installed at the entrance of a $90^{\circ}$ water intake with angles of attack of $20^{\circ}$ to the flow under sediment feeding conditions. The single column of 3 vanes reduced the amount of sediment by $20 \%$ in the intake flume. The maximum scour occurs at the entrance corner of the intake in the downstream part of the main flume. It is seen that local scour in the entrance of the intake can be reduced by using submerged vanes. During the with vane conditions, sediment transported faster along the main flume and intake took less sediment inside under sediment feeding.

\section{Acknowledgement}

The author wishes to express her special and sincere thanks to Prof. Dr. Antonio Heleno Cardoso and Instituto Superior Técnico (IST) Hydraulic Laboratory. 


\section{References}

1. Nakato, T., Model investigation of intake-shoaling and pump-vibration problems: Iowa Generation Council Bluffs Unit 3 circulating-water intake. IIHR report ;283. 1984, Iowa City: Iowa Institute of Hydraulic Research, The University of Iowa. vi, 67 p.

2. Wang, Y., Odgaard, A.J., Melville, B.W., Jain, S.C., Sediment Control at Water Intakes. Journal of Hydraulic Engineering, 1996. 122(6): p. 353-356.

3. Barkdoll, B.D., Hagen, B.L., and Odgaard, A.J., Sediment exclusion at hydropower intakes using submerged vanes. 1995: American Society of Civil Engineers, New York, NY (United States). Medium: X; Size: pp. 1915-1924.

4. $\quad$ Odgaard, A.J., Spoljaric, A., Sediment Control by Submerged Vanes. Journal of Hydraulic Engineering, 1986. 112(12): p. 1164-1180.

5. Ouyang, H., Lu, C., Optimizing the Spacing of Submerged Vanes across Rivers for Stream Bank Protection at Channel Bends. Journal of Hydraulic Engineering, 2016. 142(12): p. 04016062 .

6. Kasthuri, B. and N.V. Pundarikanthan, Discussion on Separation Zone at Open Channel Junctions. Journal of Hydraulic Engineering, 1987. 113(4): p. 543-548.

7. Nakato, T., Kennedy, J.F. and Gauerly, D. Pump-Station Intake-Shoaling Control with Submerged Vanes. Journal of Hydraulic Engineering, 1990. 116(1): p. 119-128.

8. Barkdoll, B.D., Ettema, R. and Odgaard, A.J. Sediment Control at Lateral Diversions: Limits and Enhancements to Vane Use. Journal of Hydraulic Engineering, 1999. 125(8): p. 862-870.

9. Herrero, A., Bateman, A. and Medina, V., Water flow and sediment transport in a $90^{\circ}$ channel diversion: an experimental study, Journal of Hydraulic Research, 2015. 53:2, 253263

10. Odgaard, A.J., Kennedy, F.J., River-Bend Bank Protection by Submerged Vanes. Journal of Hydraulic Engineering, 1983. 109(8).

11. Odgaard, A.J., Wang, Y., Sediment management with submerged vanes. II: Applications. Journal of Hydraulic Engineering, 1991. 117(3), 284-302.

12. Neary, V.S., Sotiropoulos, F., Odgaard, A.J., Three-Dimensional Numerical Model Of Lateral-Intake Inflows. Journal of Hydraulic Engineering, 1999. 125(2), 126. 